\title{
Excess Benefit Allocation in Shared Savings Based on Non-cooperative Game Theory
}

\author{
$\mathrm{Xiao} \mathrm{Xu}^{*}$ \\ Jinan Engineering Vocational Technical College, Jinan 250200, Shandong Province, China \\ *Corresponding author: Xiao Xu, jnepxu@sina.com
}

\begin{abstract}
Energy saving income distribution mode is of great significance to the energy industry. With the continuous application of new technologies, the problem of excess energy saving income distribution has become one of the obstacles to the appreciation of energy performance. At present, the distribution of risk and income is mainly based on the contribution of risk and income, which has some limitations. The benefit distribution of energy saving negotiation between energy saving service companies and clients can be regarded as a bargaining process where an effective range satisfying both parties can be obtained. This provides a new perspective in solving the problem of excess energy saving income distribution in energy management contract projects.
\end{abstract}

Keywords: Contract energy management; Excess energy saving; Non-cooperative game theory; Bargaining model

Publication date: August 2021; Online publication: August 30, 2021

\section{Introduction}

With the enhancement of the society's awareness of environmental protection and energy conservation, energy performance contracting (EPC) has gradually evolved into an effective way to improve the energy efficiency in China ${ }^{[1]}$. Among many contract modes of EPC project, the shared savings model (SSM) is accepted by many people including energy service companies and their clients, namely energy users.

Based on the SSM model, there have been many researchers on energy saving income distribution in recent years such as Zhu Dongshan, et al.; Zeng Zhihong and others have built a model based on fuzzy comprehensive evaluation to solve the problem of benefit distribution of energy contract management ${ }^{[6]}$; Lu Zhijian and others have constructed the energy saving income distribution model based on cooperative game theory under the condition of complete information to analyze the decision-making behavior of both sides ${ }^{[7]}$. However, the above researchers ignored a more important issue: When the energy saved by the energy service company (ESCO) through some reasonable ways exceeds the original energy saving quota, how then to allocate the excess energy saving benefits? Based on the bargaining model of non-cooperative game, this article studies the distribution of excess energy saving income and tries to obtain a satisfactory result.

\section{Problem description}

ESCO and European Union (EU) signed a revenue distribution contract for SSM-EPC. In the stage of no energy saving income, there is no energy saving income distribution between the two parties. In the later stage, ESCO has withdrawn from the energy saving benefit-sharing mechanism and does not exist. Therefore, this article mainly studies the allocation of excess energy saving benefits in SSM-EPC project in the stage of generating energy saving benefits. 
It is assumed that the expected energy saving benefits, $\mu_{b}\left(\mu_{b}>0\right)$, of both parties at this stage are the actual benefits, $\mu_{r}\left(\mu_{r}>0\right)$. When $\mu_{r}>\mu_{b}$, that is the occurrence of excess energy saving income. If the energy saving income is distributed by the United Nations Educational, Scientific, and Cultural Organization (UNESCO) and EU in a fixed proportion, the effort and enthusiasm of UNESCO for energy saving would be greatly restrained. In the event of excess energy saving benefits, EU would still distribute the excess energy saving benefits at a fixed rate of $\alpha$. Under the condition that the sunk costs of ESCO are taken into account, the distribution proportion of ESCO benefits will increase at a lower rate, $1-\alpha$. At this time, the unequal benefits and efforts of ESCO would greatly weaken the enthusiasm of UNESCO in striving to achieve excess energy saving benefits, thus leading to the failure of the project to achieve optimal energy saving benefits.

Therefore, in the case of excess energy saving income, it is extremely important to optimize the distribution scheme to satisfy both parties of the contract in solving the problem of excess energy saving income distribution.

\section{Model}

\subsection{Basic assumptions}

The main assumptions of Rubinstein bargaining model are as follows:

(1) Rational behavior: ESCO and its client are rational people where both parties want to get as much income as possible in the course of negotiation. Binmore et al. ${ }^{[8]}$ pointed out two meanings to rationality: People are fully aware of their preferences and weaknesses, and people are aware of the behaviors that best satisfy this preference. Nash ${ }^{[9]}$ pointed out the rules of the bargaining game:

(a) Players are free to choose their own strategies in each link.

(b) Each player will choose a different strategy after weighing the benefits.

(c) Every player will maximize rationality ${ }^{[10]}$.

(2) The information is complete where in the shared savings EPC project, ESCO and its client share all project information.

(3) Bargaining income: The players participating in the game obtain benefits through bargaining ${ }^{[11]}$ This article uses the distribution ratio between ESCO and its client to measure revenue ${ }^{[12]}$.

(4) Fixed cost of bargaining: In each round of negotiation, there would be fixed costs.

(5) Discount factor: A key variable that reflects the patience of participants and affect the bargaining process as well as the benefits of both parties ${ }^{[13]}$.

\subsection{Model description}

In this model, two players share a piece of cake. Player 1 bids first, and player 2 has two choices of whether to accept or reject. If player 2 accepts, the game ends, and the cake would be allocated according to player 1 's plan. However, if player 2 rejects player 1's bid, he or she needs to bid. Similarly, player 1 can then choose to accept or reject the bid. If player 1 accepts, the game is over, and the cake would be allocated according to player 2's plan. If player 1 rejects player 2's bid, then player 1 should bid again. This process would be repeated until one party's offer is accepted by the other party ${ }^{[13]}$.

Although Shaked and Sutton modified and simplified Rubinstein's original evidence, Rubinstein proved the subgame perfect equilibrium of only Pareto efficient in bargaining ${ }^{[14]}$. Based on this method, the unique subgame perfect equilibrium of Rubinstein bargaining model is proved as follows: 
First, making the assumption where $\delta_{1}$ and $\delta_{2}$ are the discount coefficients representing player 1 and player 2. $x$ is player 1's share, and $1-x$ is player 2's share. $x_{1}$ and $1-x_{1}$ represent the shares of player 1 and player 2, respectively after player 1 bids whereas $x_{2}$ and $1-x_{2}$ represent the shares of player 1 and player 2, respectively after player 2 bids.

In uncertain bargaining game theory, $T=\infty$ without a final stage, backward induction cannot be used to obtain a feasible solution. According to Shaked and Sutton's research ${ }^{[15]}$, the subgame starts from the stage where player 1 makes the first bid, $t=1$, which is equivalent to the beginning of the entire game. Backward induction of the finite stage can help to find the perfect equilibrium of subgames.

On the one hand, assuming $t(t \geq 3)$ in the game, player 1 bids first. The maximum share player 1 can get is $M$ while player 2 gets $1-M$. For player $1, t$ of $M$ is equal to $t-1$ of $\delta_{1} M$, and player 2 knows that $t-1$ anything of $x_{2} \geq \delta_{1} M$ would be accepted by player 1 . Therefore, player 2 would provide $x_{2}=\delta_{1} M$ or $x=1-\delta_{1} M$. Anything that is similar to player $2, t-1$ is equivalent to anything that $1-$ $\delta_{1} M$ player $1 \delta_{2}\left(1-\delta_{1} M\right)$ knows $x_{1} \leq 1-\delta_{2}\left(1-\delta_{1} M\right)$ is acceptable to player 2 . Therefore, player 1 would provide $x_{1}=1-\delta_{2}\left(1-\delta_{1} M\right)$ or $x_{1}=\delta_{2}\left(1-\delta_{1} M\right)$.

The game from the start $t-2$ is the same as the game from the start $t$.

In addition, the maximum share that player 1 can get in game $t-2$ is the same as his share $t$ in game which gives player 1 a unique balance:

$$
x=1-\frac{\delta_{2}}{1-\delta_{1} \delta_{2}}
$$

\subsection{First mover and second mover advantage}

The equilibrium of bargaining is asymmetric. The first bidder and the second bidder each have their own advantages, that is, the advantages of the first mover and the second mover, respectively ${ }^{[17]}$.

When players have the same discount rate, it means there is a first-mover advantage. If every player is patient enough, in particular $\delta_{1}=\delta_{2}=\delta=1$, the player would reject any bid and wait for the whole game to end. Therefore, the second bidder is in an advantageous position. Real-world players would not have that much patience.

The advantage of the laggard lacks practical significance. Participants in the negotiation should strive for the priority bid. The laggard who loses the advantage of the first bid does not mean that he or she is completely passive. Conversely, the passive participant should shorten the counteroffer time because the first mover advantage will disappear if the time interval approaches 0 and $\delta$ tends to 1 . Each participant will receive half of the "cake" ${ }^{[13]}$, that is, $x_{1}^{*}=x_{2}^{*}=\frac{1}{2}$.

\section{Results}

\subsection{Effective bargaining range}

Energy saving benefit distribution, also known as benefit distribution, is one of the key factors for the success of shared savings general contract. The welfare allocation quota (what to allocate) is the target of ESCO in the general contract with its client. This quota defines an allocation interval to ensure the basic interests of both parties. In addition, this distribution interval is also the size of the whole "cake" in bargaining theory; that is the effective bargaining interval.

\subsubsection{Energy saving goals of ESCO and the client}

After deducting the cost, the remaining energy savings $N P V\left(T_{f}\right)$ become the player's goal. The benefits that are distributed by ESCO are $N P V_{e}$ and the benefits that are distributed by the client are $N P V_{c}$. The 
total energy efficiency index consists of $C_{t}$ and $T_{f}$ net present value. As a result, ESCO and the client recouped their costs after the allocation $\operatorname{NPV}\left(T_{f}\right)$.

The renovation project is completed on schedule $T_{1}$ and energy conservation is generated. The net present value $T_{2}$ of the project is above 0 . In addition, the net present value $T_{3}$ of the project will be at its peak. However, NPV starts to fall as the cost of operation and maintenance increases. The whole economic life cycle is $T_{f}$. The net present value generated during this period is $\operatorname{NPV}\left(T_{f}\right)$.

\subsubsection{Upper limit of effective bargaining range}

Clients are concerned about the duration of benefit distribution and the residual economic life cycle distribution.

In the bargaining model of profit distribution, when clients have the opportunity to share the income, and the project has a considerable net present value, they would benefit from the project.

$$
N P V_{c} \geq 0
$$

Thus, the upper limit of the effective $N P V\left(T_{f}\right)$ bargaining interval is defined from the perspective of ESCO.

\subsubsection{Lower limit of effective bargaining range}

When ESCO and its client enter into a transaction and sign an energy agreement service contract, the cost of ESCO during the contract period includes two parts: One of it is the equipment related to energy service products, and the other is the cost incurred in the process of construction management and maintenance ${ }^{[15]}$.

ESCO is driven by profit, which is why ESCO wants to successfully complete the energy conservation project. IR is set as the lower limit of the effective bargaining range.

From ESCO's point of view, the overall size of the cake is $N P V\left(T_{f}\right)-I R$. ESCO and its client need to reach a more specific negotiated outcome within this time interval to ensure that the allocation moves ahead as planned.

\subsection{Energy saving benefit distribution scheme (how to distribute)}

Since the effective bargaining interval has been defined, this section uses the bargaining theory in the process between ESCO and its client to establish the energy saving benefit allocation model of shared energy saving EPC.

\subsubsection{Bargaining process and parameter setting}

In this bargaining process, two participants bid in turn where the other party either accepts or rejects. When one player's offer is accepted by another player, the game ends. The process is divided into two parts: Client bids first or ESCO bid first.

(1) Client bids first

When a client makes an offer, ESCO chooses to accept or reject it. Either ESCO accepts the conclusion of the negotiation process or ESCO would need to fight back. Assuming that $P_{e}$ in this case is ESCO's maximum income whereas the minimum income is $p_{e}$.

(2) ESCO bid first

When ESCO first makes an offer, the client chooses to accept or reject it. If the client accepts, the negotiation process ends, otherwise, the client needs to fight back. Assuming $P_{c}{ }^{\prime}$ in this case is the highest revenue for the client and the lowest revenue for ESCO are represented. 


\subsubsection{Model construction}

The first bidder has an advantage in the negotiation process. Therefore, the bargaining process is based on the following two possibilities:

(1) Client bids first

a) Perhaps ESCO would argue that taking into account of the direct fixed costs, $f_{e}$ and attrition rates, $\delta_{e}$, ESCO's maximum benefit is $\delta_{e} P_{e}-f_{e}$, and the minimum income is $\delta_{e} p_{e}-f_{e}$.

To avoid ESCO's counteroffer, the client can provide the first round of allocation interval, $\left[\delta_{e} p_{e}-f_{e}, \delta_{e} P_{e}-f_{e}\right]$, which is the same as the floating interval obtained in the second round of the game after ESCO's counteroffer. This is the best strategy for the client.

As mentioned earlier, the size of the cake is $N P V\left(T_{f}\right)-I R$. If the client uses the strategy in the previous paragraph to allocate this cake to ESCO, the client's maximum gain is $\left[N P V\left(T_{f}\right)-I R\right]-\left(\delta_{e} p_{e}-f_{e}\right)$ whereas the minimum gain is $\left[N P V\left(T_{f}\right)-I R\right]-\left(\delta_{e} P_{e}-\right.$ $f_{e}$ ). Based on the above assumptions, the highest $P_{c}$ and lowest $p_{c}$ income of the client are known.

b) If ESCO makes an offer, the client may reject ESCO's counteroffer and bid again. If the client does so, he or she is responsible for the direct fixed costs, $f_{c}$ and the secondary discount rate, $\delta_{c}$. In addition, the client's maximum benefit is $\delta_{c} P_{c}-2 f_{c}$ whereas the minimum income is $\delta_{c} p_{c}-2 f_{c}$. In order to avoid a second bid from the client, ESCO could offer a first allocation interval, $\left[\delta_{c} p_{c}-2 f_{c}, \delta_{c} P_{c}-2 f_{c}\right]$, equal to the second negotiation interval after the client's bid, which is perhaps ESCO's best strategy.

According to the above strategy, the maximum and minimum benefits of ESCO are $\left[N P V\left(T_{f}\right)-I R\right]-\left(\delta_{c} p_{c}-2 f_{c}\right)$ and $\left[N P V\left(T_{f}\right)-I R\right]-\left(\delta_{c} P_{c}-2 f_{c}\right)$, respectively.

$P_{e}$ represents ESCO's expected maximum revenue and $p_{e}$ represents ESCO's expected minimum revenue.

According to Shaked and Sutton ${ }^{[15]}$, when a client bids first, the maximum return of the client is equal to the minimum return, and the equilibrium result is unique. Therefore, the client's equilibrium bidding strategy is $P_{c 1}$.

$$
P_{c 1}=\frac{\left(1-\delta_{e}\right)\left[N P V\left(T_{f}\right)-I R\right]-2 \delta_{e} f_{c}+f_{e}}{1-\delta_{e} \delta_{c}}
$$

In this case, the upper limit, $\left[N P V\left(T_{f}\right)-P_{c 1}\right]$, is redefined as the interval between the distribution of energy efficiency benefits.

(2) ESCO bid first

a) The client can argue back. As reasonable people, if ESCO's offer is not attractive enough, the client may turn it down. Clients need to consider direct fixed costs, $f_{c}$ and discount factors, $\delta_{c}$. Therefore, the maximum benefit for the client is $\delta_{c} P^{\prime}{ }_{c}-f_{c}$, and the minimum income is $\delta_{c} p_{c}^{\prime}-f_{c}$.

In order to avoid a counteroffer, ESCO can offer the distribution interval in the first round $\left[\delta_{c} p_{c}^{\prime}-f_{c},\right] \delta_{c} P_{c}^{\prime}-f_{c}$, which is the same as the floating interval in the second round of the game after the client has changed trades. This is ESCO's best strategy.

As mentioned earlier, the size of the "cake" is $N P V\left(T_{f}\right)-I R$. If ESCO and the client allocate the "cake" with this strategy in the first stage, the maximum gain is $\left[N P V\left(T_{f}\right)-\right.$ $I R]-\left(\delta_{c} P_{c}^{\prime}-f_{c}\right)$, and the minimum gain is $\left[N P V\left(T_{f}\right)-I R\right]-\left(\delta_{c} p_{c}^{\prime}-f_{c}\right)$. 
Based on the above assumptions, we know that ESCO's maximum income is $P_{e}^{\prime}$ whereas the minimum income $p_{e}^{\prime}$.

b) If the client objects, he or she may make a new bid. ESCO may reject the client's counteroffer and make another bid. If ESCO were to do so, it would incur direct fixed costs, $f_{e}$ and double the discount rate, $\delta_{e}$. In addition, ESCO's highest income is $\delta_{e} P_{e}^{\prime}-2 f_{e}$ and the lowest income is $\delta_{e} p_{e}^{\prime}-2 f_{e}$.

In order to avoid a second ESCO bid, the client could offer an allocation interval, $\left[\delta_{e} p_{e}^{\prime}-\right.$ $\left.2 f_{e}, \delta_{e} P^{\prime}{ }_{e}-2 f_{e}\right]$, in the first round equal to the second negotiating interval after ESCO's bid, which is probably the best strategy for the client.

According to the above strategy, the client's maximum return is $\left[N P V\left(T_{f}\right)-I R\right]-$ $\left(\delta_{e} p_{e}^{\prime}-2 f_{e}\right)$, and the minimum return is $\left[N P V\left(T_{f}\right)-I R\right]-\left(\delta_{e} P_{e}^{\prime}-2 f_{e}\right)$.

The expected maximum $P_{e}^{\prime}$ and minimum benefits $p_{e}^{\prime}$ of ESCO:

$$
P_{e}^{\prime}=p_{e}^{\prime}=\frac{\left(1-\delta_{c}\right)\left[N P V\left(T_{f}\right)-I R\right]-2 \delta_{c} f_{e}+f_{c}}{1-\delta_{e} \delta_{c}}
$$

According to Shaked and Sutton ${ }^{[15]}$, when ESCO bids first, the maximum income is the same as the minimum income, and the equilibrium result is unique.

Therefore, ESCO's equilibrium bidding strategy is $P_{e 1}^{\prime}$.

$$
P_{e 1}^{\prime}=\frac{\left(1-\delta_{c}\right)\left[N P V\left(T_{f}\right)-I R\right]-2 \delta_{c} f_{e}+f_{c}}{1-\delta_{e} \delta_{c}}
$$

In this case, $I R+P_{e 1}^{\prime}$ is redefined as the lower limit of the allocation interval for energy efficiency benefits.

\section{Conclusion}

By analyzing the bargaining process, the two sides balanced the bidding discussion allocation strategy. At the same time, considering the value of money and risk factors, the interest distribution period and the distribution ratio can be calculated to solve the problem of how to distribute. This method can help ESCO and the clients to reasonably allocate and share energy-saving benefits of energy-saving EPC projects.

First, the income distribution scheme is based on the net present value and calculated according to the nominal interest rate of the bank after discounting, but this evaluation method also has limitations. Second, the discussion about the acceptable accuracy of interest distribution interval reflects the subjective understanding of both sides. Therefore, the discussion is not accurate enough. Third, considering the time value of money and risk factors to discuss the benefit distribution period and determine the distribution proportion of the total energy-saving benefits. However, there is no further research on this issue. Hence, future research should specifically illustrate this point, and find the relationship through the establishment of mathematical models.

\section{Disclosure statement}

The author declares that there is no conflict of interest. 


\section{References}

[1] Zhang X, Wu Z, Feng Y, et al., 2015, "Turning Green into Gold": A Framework for Energy Performance Contracting (EPC) In China's Real Estate Industry. Journal of Cleaner Production, 109: 166-73.

[2] Xu P, Chan HW, Qian QK, 2011, Success Factors of Energy Performance Contracting (EPC) for Sustainable Building Energy Efficiency Retrofit (BEER) of Hotel Buildings in China. Energy Policy, 39(11): 7389-98.

[3] Lee P, Lam PTI, Lee WL, 2015, Risks in Energy Performance Contracting (EPC) Project. Energy Build, 92: 116-27.

[4] Deng T, Hu F, Wei H, 2012, Benefit and Risk Analysis on Renovation Projects of Contract Energy Management Company for Energy Saving in China. International Conference on Electric Information \& Control Engineering, 21(3): 202-5.

[5] Zhu D, Kong Y, 2016, Research on Benefit Distribution Ratio between Energy Management Company and Users Under Contract Energy Management Mode. Ecological economy, 32(11): 59-64.

[6] Zeng Z, 2014, Based on the Comprehensive Evaluation, the Benefit Distribution of the Sharing Contract Energy Management Project. Journal of Wuhan University of technology, 36(8): 144-8.

[7] Lu Z, Sun Y, 2015, Game Model of Energy Saving Benefit Sharing Mode of Contract Energy Management Under Complete Information. Science and Technology Management Research, 24: 2169.

[8] Binmore K, Rubinstein A, Wolinsky A, 1986, The Nash Bargaining Solution in Economic Modelling. Rand J Econ, 17: 176-88.

[9] Nash JF, 2002, The Bargaining Problem, The Essential John Nash.

[10] Shen LY, Bao HJ, Wu YZ, et al., 2007, Using Bargaining-Game Theory for Negotiating Concession Period for BOT-Type Contract. Journal of Construction Engineering and Management, 133(005): 385 92.

[11] Nash JF, 1950, Equilibrium Points in N-Person Games. Proceedings of the National Academy of Ences, 36(001): 48-9.

[12] Xie SY, 2008, Economic Game Theory, Fu Dan University Press, Shanghai.

[13] Zhang C, Zhu X, 2015, PBL Tutorial: Game Theory and Information Economics, People's Posts and Telecommunications Press.

[14] Guan YP, 2005, Bargaining Theory and Application, Shanghai University of Finance and Economics Press, Shanghai.

[15] Shaked A, Sutton J, 1984, Involuntary Unemployment as a Perfect Equilibrium in a Bargaining Game. Econometrica, 52: 1351-64.

[16] Zhang Y, Shen J, 2016, The Evolution of China's Energy Conservation and Emission Reduction Policies - Based on the Policy Texts from 1978 to 2016. Journal of China University of Petroleum (Social Science Edition), 032(006): 1-5.

[17] Chen J, 2012, Supply Chain Benefit Game Based on Bargaining Model. Logistics Engineering and Management, 34(004): 83-4. 